Proc. of the 15th Int. Workshop on Slow Positron Beam Techniques and Applications, Prague, September 2-6, 2019

\title{
Positron Annihilation Spectroscopy Characterization of Formation of Helium/Hydrogen-Vacancy Nano-Clusters in FeCr Alloy
}

\author{
Te Zhu ${ }^{a, b, c}$, Baoyi Wang ${ }^{a, c}$, Xiangyu Lian ${ }^{a}$, Shuoxue Jin ${ }^{a}$, Runsheng Yu ${ }^{a}$, \\ Xingzhong $\mathrm{CAO}^{a, *}$ AND QIU XU ${ }^{b}$ \\ ${ }^{a}$ Multi-discipline Research Center, Institute of High Energy Physics, CAS, Beijing 100049, China \\ ${ }^{b}$ Institute for Integrated Radiation and Nuclear Science, Kyoto University, Kumatori-cho, Osaka 5900494, Japan \\ ${ }^{c}$ University of Chinese Academy of Sciences, Beijing 100039, China
}

\begin{abstract}
In the present work, Fe9Cr model alloy was implanted with $100 \mathrm{keV} H e$ and $60 \mathrm{keV} \mathrm{H}$ ions at room temperature. Positron annihilation Doppler broadening spectroscopy was employed to detect $(\mathrm{H}, \mathrm{He})-\mathrm{V}$ complexes with open volume in the irradiated specimens. The results show that the positron is sensitive to the relative position of the gas atoms decorating the open volume; i.e., to the configuration of the $(\mathrm{H}, \mathrm{He})-\mathrm{V}$ complexes. The formation of $\mathrm{H}$-vacancy clusters after $\mathrm{H}$ implantation and a large number of vacancies can be retained after $\mathrm{H}-\mathrm{V}$ decomposes at room temperature. For the pre-implanted He situation $(\mathrm{He}+\mathrm{H})$, He-vacancy clusters are formed in advance and the post-implanted $\mathrm{H}$ introduces a large number of vacancies and decomposable $\mathrm{H}$-vacancy clusters. The $\mathrm{He}-$ vacancy clusters forming in advance may recombine with vacancies and $\mathrm{H}$ atoms to form stable He-vacancy clusters and a small amount of $\mathrm{He}-\mathrm{H}-\mathrm{V}$ complex.
\end{abstract}

DOI: 10.12693/APhysPolA.137.235

PACS/topics: slow positron beam, helium/hydrogen-vacancy clusters, irradiation damage

\section{Introduction}

Shallow traps formed by helium/hydrogen and vacancies, namely $(\mathrm{H}, \mathrm{He})-\mathrm{V}$ nanoclusters, are common in various alloys, and nuclear energy structural materials are good examples. The high neutron flux will cause the continuous production of both hydrogen and helium in structural materials within the reactor via $(\mathrm{n}, \mathrm{p})$ and $(\mathrm{n}, \alpha)$ transmutation reactions. As a result, swelling and embrittlement of the materials can occur by the accumulation of hydrogen and helium [1-3]. Reported works indicate that hydrogen/helium atoms could interact with irradiation-induced vacancy defects, and they could also migrate and aggregate to form $(\mathrm{H} / \mathrm{He})-\mathrm{V}$ clusters or bubbles, which might cause undesired changes in the material properties $[4,5]$.

The atomic-scale defects such as $(\mathrm{H}, \mathrm{He})-\mathrm{V}$ clusters are the main cause of the deterioration of the macroscopic properties of materials. Unfortunately, they cannot be observed by transmission electron microscopy before they grow to the nanometer scale. Positron annihilation spectroscopy (PAS) has been proved to be sensitive to open-volume defects, and could characterize the evolution of the size and concentration of the open-volume defects [6]. This is because open-volume defects, in neutral or negative charge states, act as efficient positron traps because of the reduced repulsion of positive ions.

*corresponding author; e-mail: caoxzh@ihep.ac.cn
However, the positron trapping at hydrogen/heliumvacancy complexes is not very easy because hydrogen and helium affects the electron density and distribution of defects in metals and alloys. The purpose of the study was to characterize the formation of $(\mathrm{H} / \mathrm{He})-\mathrm{V}$ clusters and to identify the types of defects in the $\mathrm{Fe} 9 \mathrm{Cr}$ alloys after $\mathrm{H} / \mathrm{He}$ irradiation with different implantation patterns by PAS.

\section{Experiments}

\subsection{Materials and hydrogen/helium ion irradiation}

The $\mathrm{Fe} 9 \mathrm{Cr}$ samples used in this study were fabricated from high purity $\mathrm{Fe}$ (99.99\%) and $\mathrm{Cr}$ (99.99\%) metals by an arc melting process at General Research Institute for Nonferrous Metals. The bulk materials for irradiation experiments were first cut to a thickness of $0.3 \mathrm{~mm}$ in $10 \mathrm{~mm} \times 10 \mathrm{~mm}$ square sheets and then mechanically polished with $\mathrm{SiC}$ sandpapers up to ${ }^{\#} 4000$, followed by a thorough annealing at $1100 \mathrm{~K}$ for $2 \mathrm{~h}$ in vacuum $\left(\approx 10^{-5} \mathrm{~Pa}\right)$.

The irradiation experiments were divided into four subgroups: in the first case, only $\mathrm{H}$ ions were implanted into the specimen, whereas the second specimen was irradiated with $\mathrm{He}$ ions. In the third case, He ions were implanted into the specimen before $\mathrm{H}$ ions (i.e., $\mathrm{He}+\mathrm{H}$ ). The last pattern was just like the third one except with the opposite sequence (i.e., $\mathrm{H}$ followed by $\mathrm{He}$ ). The energies of the hydrogen and helium ion beams were fixed at $60 \mathrm{keV}$ and $100 \mathrm{keV}$, respectively, to make the peak concentration of ions overlap at about $330 \mathrm{~nm}$ according 


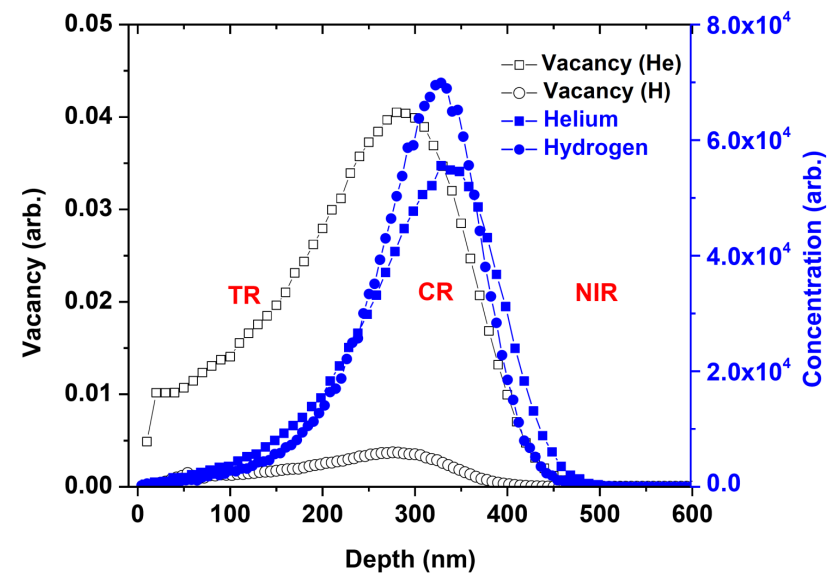

Fig. 1. Profiles of damage and atom concentration in Fe9Cr alloy irradiated with $100 \mathrm{keV} \mathrm{He}^{2+}$ and $60 \mathrm{keV}$ $\mathrm{H}^{+}$calculated with SRIM.

to the calculation of the SRIM code [7]. The doses of He and $\mathrm{H}$ were $1 \times 10^{16}$ ions $/ \mathrm{cm}^{2}$ (6680 appm at the peak) and $5 \times 10^{16}$ ions $/ \mathrm{cm}^{2}(42960$ appm at the peak), respectively. The profiles of damage and the concentration of implanted $\mathrm{H}$ and He ions obtained by SRIM are plotted in Fig. 1.

\subsection{Positron annihilation spectroscopy measurements}

Slow positron beam Doppler broadening experiments were performed at room temperature using an energyvariable slow positron beam facility. Positrons were generated by a $50 \mathrm{mCi}{ }^{22} \mathrm{Na}$ radiation source, and then moderated by tungsten. Monoenergetic positron within the energy range of $0.18-20 \mathrm{keV}$ were implanted into the specimens [8]. Two parameters, namely the $S$ and $W$ parameters, were introduced to characterize the information about the specimens. The $S$ parameter, which describes the case of positron annihilation with a valence electron, was defined as the ratio of counts in the central energy region around $511 \mathrm{keV}$ $(510.2-511.8 \mathrm{keV})$ to the total $\gamma$ photo counts in the complete range of 499.5-522.5 keV [9]. Consequently, an increase in the $S$ parameter indicates the presence of vacancy-like defects with open volume. The $W$ parameter, which describes the case of a positron annihilated with a core electron, was defined as the ratio of counts in the wing areas (505.1-508.4 keV and 513.6-516.9 keV) to the total counts.

\section{Results and discussion}

In Fig. 2, the $S$ parameter and $\Delta S / S(\Delta S / S=$ $\left.\left(S_{\text {irradiated }}-S_{\text {unirradiated }}\right) / S_{\text {unirradiated }}\right)$ are presented as a function of incident positron energy $E$ to obtain defect distribution profiles in unirradiated and $\mathrm{H} / \mathrm{He}$ irradiated specimens. The mean positron implantation depth (in $\mathrm{nm}$ ) is given by $40000 E^{1.6} / \rho$, where $E$ is the incident positron energy in units of $\mathrm{keV}$ and $\rho$ is the density of the
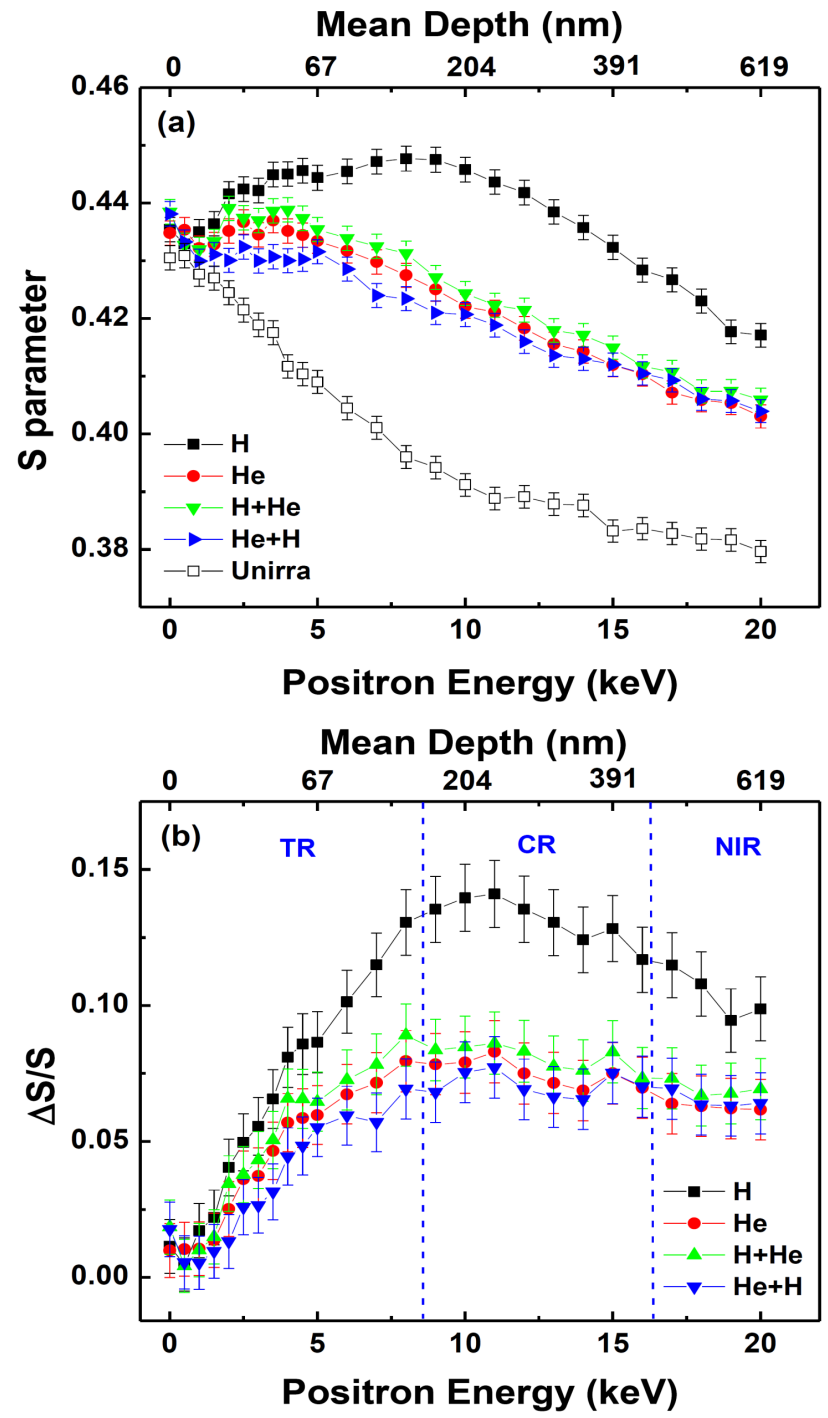

Fig. 2. The $S$ parameter (a) and $\Delta S / S$ (b) as a function of incident positron energy (mean implantation depth) in unirradiated and irradiated $\mathrm{Fe} 9 \mathrm{Cr}$ alloys.

alloy in units of $\mathrm{kg} / \mathrm{m}^{3}$. It can be seen that in the range of interest, the $S$ parameters for all the irradiated specimens are much higher than that of the unirradiated sample; this verifies the production of large amounts of vacancytype defects by $\mathrm{H} / \mathrm{He}$ irradiation. The $S(E)$ curve for the unirradiated specimen in Fig. 2a is a typical curve shape for well-annealed metals, which decreases with positron energy near the surface and then reaches a stable value above $10 \mathrm{keV}[10]$. The $\Delta S / S$ parameter could clearly reflect the increment of the vacancy-type defects concentration after $\mathrm{H} / \mathrm{He}$ irradiation. According to the vacancy distribution profiles in the SRIM calculation, $\Delta S / S-E$ curves were divided into three layers in Fig. $2 \mathrm{~b}$. The first layer is the tracks region (TR) where ions slow down mainly by electronic energy loss processes. CR denotes the cascades region, corresponding to the zone where incident ions mainly interact with the lattice atoms via 
nuclear collisions and finally come to rest in the lattice. NIR denotes the non-implanted region. The boundaries of TR and CR are at about $10-180$ and $180-460 \mathrm{~nm}$, respectively, $\mathrm{H} / \mathrm{He}$ ions were implanted to depths of about $500 \mathrm{~nm}$, and surface-to-peak depths were about $330 \mathrm{~nm}$. Therefore, a large number of vacancies were generated by ion irradiation in the TR and CR. However, an elevated $S$ parameter is also found in the NIR, suggesting the presence of vacancy-type defects in the region. This fact demonstrates that vacancy-type defects induced by irradiation migrate toward the NIR. Dimitrov et al. [11-13] assumed that vacancies migrate in the $260-460 \mathrm{~K}$ range in steel. In the $\mathrm{CR}$, the effective open volume, represented by the $\Delta S / S$ parameter, was larger in the sample exposed to $\mathrm{H}$ irradiation than for those irradiated with $\mathrm{He}$ or mixtures of $\mathrm{He}$ and $\mathrm{H}$. This can be explained by formation of $\mathrm{H}$-vacancy clusters after $\mathrm{H}$ implantation. However, the binding energy between the $\mathrm{H}$ and the vacancy is small and a large number of vacancies can be retained after $\mathrm{H}-\mathrm{V}$ decomposes at room temperature [14]. On the other hand, post-implanted helium can trap the vacancies decomposed from $\mathrm{H}$-vacancy clusters as well as self-generated to form He-vacancy clusters, resulting in a value of $\Delta S / S$ that is lower than that of single $\mathrm{H}$ irradiation situation. For the pre-implanted He situation $(\mathrm{He}+\mathrm{H})$, He-vacancy clusters formed in advance and the post-implanted $\mathrm{H}$ introduces a large number of vacancies and decomposable $\mathrm{H}$-vacancy clusters. The He-vacancy clusters forming in advance may recombine with vacancies and $\mathrm{H}$ atoms to form stable He-vacancy clusters and a small amount of $\mathrm{He}-\mathrm{H}-\mathrm{V}$ complex.

\section{Conclusions}

Positron annihilation Doppler broadening spectroscopy were employed to detect $(\mathrm{H}, \mathrm{He})-\mathrm{V}$ complexes with open volume in ion-irradiated $\mathrm{Fe} 9 \mathrm{Cr}$ alloys. The results show that formation of $\mathrm{H}$-vacancy clusters after $\mathrm{H}$ implantation and a large number of vacancies can be retained after $\mathrm{H}-\mathrm{V}$ decomposes at room temperature. For the pre-implanted $\mathrm{He}$ situation $(\mathrm{He}+\mathrm{H})$, He-vacancy clusters are formed in advance and the post-implanted $\mathrm{H}$ introduces a large number of vacancies and decomposable $\mathrm{H}$-vacancy clusters. The He-vacancy clusters forming in advance may recombine with vacancies and $\mathrm{H}$ atoms to form stable He-vacancy clusters and a small amount of $\mathrm{He}-\mathrm{H}-\mathrm{V}$ complex.

\section{Acknowledgments}

The authors are grateful for the financial supports by the National Natural Science foundation of China (Grant Nos. 11475193, 11505192, U1732265, 11775235, 11775236, 11505205, and 11675188). We thank Professor Liping Guo from Wuhan University for irradiation experiments. The first author gratefully acknowledge financial support from China Scholarship Council.

\section{References}

[1] D. Kaminsky, S.K. Das, J. Nucl. Mater. 76, 256 (1978).

[2] R.E. Stoller, J. Nucl. Mater. 174, 289 (1990).

[3] V.N. Chernikov, A.P. Zakharov, P.R. Kazansky, J. Nucl. Mater. 155, 1142 (1988).

[4] P. Klaver, E. Haddeman, B. Thijsse, Nucl. Instrum. Methods Phys. Res. B 153, 228 (1999).

[5] W.D. Wilson, R.A. Johnson, in: Interactomic Potentials and Simulation of Lattice Defects - Part 3, Eds. P.C. Gehlen, J.R. Beeler, R.I. Jaffee, Plenum, New York 1972, p. 375.

[6] X. Cao, T. Zhu, S. Jin, P. Kuang, P. Zhang, E. Lu, Y. Gong, L. Guo, B. Wang, Appl. Phys. A Mater. 123, 177 (2017).

[7] Annual Book of ASTM Standards, ASTM E521, Standard Practice for Neutron Radiation Damage Simulation by Charged Particle Irradiation, Vol. 12.02, American Society for Testing and Materials, Philadelphia (PA) 1989, p. D-9.

[8] T. Zhu, S. Jin, P. Zhang, L. Song, X. Cao, B. Wang, J. Nucl. Mater. 505, 69 (2018).

[9] T. Zhu, S. Jin, L. Guo, Y. Hu, E. Lu, J. Wu, B. Wang, L. Wei, X. Cao, Philos. Mag. 96, 253 (2016).

[10] T. Iwai, H. Tsuchida, M. Awano, J. Nucl. Mater. 367, 372 (2007).

[11] C. Dimitrov, M. Tenti, O. Dimitrov, J. Phys. F Met. Phys. 11, 753 (1981).

[12] P. Zhang, S. Jin, E. Lu, B. Wang, Y. Zheng, D. Yuan, X. Cao, J. Nucl. Mater. 459, 301 (2015).

[13] T. Zhu, X. Cao, B. Wang, Q. Xu, Nucl. Instrum. Meth. Phys. Res. B 436, 35 (2018).

[14] S. Linderoth, A.V. Shishkin, Philos. Mag. A 55, 291 (1987). 